\title{
ADMINISTRATION OF A SOCIAL WORK MODEL FOR LOCAL COOPERATIVISM ${ }^{\star}$ \\ ADMINISTRACIÓN DE UN MODELO DE TRABAJO SOCIAL PARA EL COOPERATIVISMO LOCAL
}

Recibido: 22 de mayo de 2019

Evaluado: 4 de junio de 2019

Aprobado: 23 de julio de 2019

Cruz García Lirios**

Universidad Autónoma del Estado de México

Orcid: 0000-0001-9364-6796

Cómo citar este artículo: Cruz García, L. (2019). Administration of a Social Work Model for Local Cooperativism. Revista Estrategia Organizacional, 8 (2). pp. 35-48. doi: https://doi.org/10.22490/25392786.3430

* $\quad$ Artículo de investigación.

** Doctor en Psicología de la Universidad Nacional Autónoma de México.

Email: cgarcial213@profesor.uaemex.mx 


\begin{abstract}
The discussion on the relationship between social work and local cooperativism in order to administrate a model for the study of the phenomenon was the objective of this work. A study was carried out with an intentional selection of sources indexed to international repositories from 2010 to 2019 , although the design of the research limited the information to the local area, suggesting the extension of the work in other global databases.
\end{abstract}

Keywords: Cooperativism, Social Work, Model, Administration, Economy.

\title{
RESUMEN
}

El objetivo de este trabajo fue la discusión sobre la relación entre el trabajo social y el cooperativismo local para administrar un modelo para el estudio del fenómeno. Se realizó un estudio con una selección intencional de fuentes indexadas en repositorios internacionales de 2010 a 2019, aunque el diseño de la investigación limitó la información al área local, lo que sugiere la extensión del trabajo en otras bases de datos globales.

Palabras clave: cooperativismo, trabajo social, modelo, administración, economía.

\section{INTRODUCTION}

Cooperativism understood as a setting for discussion and austerity arrangements is linked to Social Work in order to promote participation, dialogue and agreements between economic, political and social actors that are immersed in problems, environmental and labor. In this sense, a review of the factors that affect community development shows that carbon dioxide emissions and child labor stand out in the disciplinary agenda (Amemiya, Valdés, Morales and García, 2018).

The objective of this paper is to expose the theoretical and conceptual axes in order to be able to construct an intervention proposal, but given the studies related to cooperativism it is necessary to consider the social asymmetries. Establish three areas of discussion from a logic of center and periphery: 1) the consequences of neoliberal globalization on the environment, more precisely the structural relations of production and reproduction super-structure of social 
domination, 2) subsequent asymmetries between society and State observed in a sociopolitical identity and. 3) the specification of an alternative of Social Work for Sustainable Cooperativist Development. Therefore, the scope and limits of the proposal are discussed, consisting of eight analytical dimensions from which local development scenarios are anticipated. In this way, the central argument of this paper is that there are different forms of cooperation that on the one hand impact vulnerable, marginalized or excluded sectors, but on the other hand they encourage discussion about its importance and generate proposals that contribute to its solution.

A documentary study was carried out with an intentional selection of sources indexed to international repositories; Dialnet, Latindex, Publindex, Redalyc and Scielo from 2010 to 2019, as well as the search by keywords.

From three rounds derived from the Delphi technique, expert judges qualified the selected extracts, considering -1 for information unfavorable to the phenomenon, 0 for disconnected elements and +1 for favorable data. The information was processed in the qualitative data analysis package (QDA by its acronym in English version 4.0).

\section{LOCAL COOPERATIVE WORK}

The Sustainable Cooperativist Development supposes conflicts for the administration of the natural resources and the public services given the gap between availability and consumption (Barranco, Delgado, Melin and Quintana, 2010).

However, the mediation of conflicts between communities or between authorities and users opens up the possibility of a new approach to Social Work and, therefore, a specialized role in the management of demands (Carreón, Hernández and García, 2016).

In this sense, local, endogenous and community development seems to depend on the supply of resources, but its consumption is not determined by internal consensus, but external as the communities share resources with other indigenous peoples or, where appropriate, municipal services they are not only the responsibility of authorities, citizen participation is also fundamental for energy or water sustainability (Eito, 2012). 
Thus, social work is immersed in a dilemma of resource management and services against self-management of local demands that contravene global agreements (Figueroa, Fierro, Martinez, Chavez and Garcia, 2017).

This paper will open the discussion of alternative scenarios to growth or development in order to establish the axes of analysis for the construction of a sociopolitical identity in which dialogue, debate and consensus are determining factors of public policies and social programs (France, 2011).

However, the present work only aims to show the scenario that prevents current generations from developing sustainably and that makes the intervention of Social Work relevant.

It is true that other disciplines have advanced in terms of sustainability proposals, but the study of conflicts between actors who share natural resources is an area of knowledge and specialization before which Social Work has the conceptual and methodological tools to anticipate scenarios disagree and from them to orient the dialogue to confront positions and reach agreements that imply the care of nature, not from an ethic or as a way of life, but as a group norm before environmental policies and water or energy supply programs (Sources, Muyor and Galinda, 2010) .

This is how climate change, global warming, the greenhouse effect and carbon dioxide emissions are concepts commonly used not because of the degree of social knowledge, not even because of the level of social representations, but rather because of the perception of risk widely disseminated the media (García, 2017).

According to the Organization for Economic Co-operationand Development(OECD for its acronym in English), the fundamental problem that inhibits economic growth and affects public health stability is the emission of $\mathrm{CO} 2$ into the atmosphere (Garcia Bustos, Carreon and Hernández, 2017).

It is estimated that each year the most developed countries emit 1,300 million tons into the atmosphere while other emerging countries such as China emit about 600 million tons per year since 1971. 
However, the most significant problem for emerging countries is the generation of municipal and residential waste.

Mexico generates about 300 kilograms of municipal waste per person while residential waste is of the order of one kilogram per capita (García, Carreón and Hernández, 2017).

In short, the emission of $\mathrm{CO} 2$ is the global problem, but the local problem is domestic and municipal waste. Both are indicative of an economic structure oriented to the reproduction of social domination since it is inferred that the consumption of energy and the generation of waste are generated by sectors with sufficient purchasing power to maintain a quality of life according to the groups of belonging (García, Juárez and Bustos, 2018).

However, it is important to note that environmental problems are related to sociodemographic variables.

This is the case of the population that is mostly concentrated in the productive and consumer life stage.

Even in terms of spaces, urban areas concentrate the greatest supply of resources in reference to rural or mixed spaces.

That is why the production and consumption of products and services are linked to social assistance (Morera, 2010). As vulnerable, marginalized and excluded groups intensify their demands, production and consumption is oriented to groups with sufficient purchasing power to generate municipal and residential waste.

In short, environmental problems are the responsibility of those who assume costly lifestyles. In front of those who live in frugality, the environmental problems are the least of the evils since it is the delivery of justice the area in which social exclusion, urban marginality and environmental vulnerability intensifies (Váldés, Amemiya and García, 2019). 
If we reflect on social exclusion and urban marginality, it is relevant to discuss its relationship with injustice. It is true that robberies are the main indicator that explains the number of reports of injuries, but the consignments are almost non-existent (Gutiérrez, García, Valdés, Anguiano, Sandoval and Campos, 2019).

In addition to the environmental and public safety issues, employment is another factor that explains the lack of opportunities, consequently the reduction of capacities and the discrediting of responsibilities (Quiroga, Vargas and Cruz, 2010).

Social security, in reference to the Economically Active Population, represents a third, but the capacity for self-management is non-existent in the face of unemployment or labor vulnerability.

It is possible to notice a significant variation between the unemployment rate according to the period from 1990 to 2004, but it is the cities with more than one million inhabitants that show the greatest historical variation.

Despite the fact that unemployment is intensifying, child labor reveals the labor informality in which the country finds itself, which impacts its most vulnerable sector (Soto, Dorner, García and Hernández, 2018).

A comparison between 2010 and 2019 allows us to anticipate that far from reducing child labor increases. Even the difference in sexes does not prevent child labor from affecting both.

The educational backwardness is a characteristic of the children who work in the cities. That is, cities can have educational centers, but a sector cannot go to them because they have to work (Veliz, Carreón, Dorner, Estay and García, 2018). That is why the bulk of the child labor force has incomplete primary education, which means that employment is not temporary and that it marginalizes it at an early age of having enough remuneration to cover basic needs.

This data correlates with the lack of interest as the main factor of desertion and shows how the educational system not only marginalizes or excludes, but also discourages those who have an occupation or unpaid employment. 
However, the second factor related to the lack of money shows that educational services are favorable to those who can afford academic resources and the continuous training of skills and knowledge (Villegas, Rosas and García, 2018). In this sense, the opportunities correspond to the capacities, but not to the responsibilities since, on the one hand, the educational budget is assigned to the payment of the teachers and other benefits and union rights, on the other hand, those who can check their stay do not they generate knowledge and are satisfied with a non-specialized training.

In summary, the environmental, social, labor and educational problems seem to affect the most vulnerable sector that children are. In this sense, Social Work is called to place emphasis on civil protection, support management, conflict mediation, personalized attention, school guidance, job training, ecological training and professional training.

\section{LABOR THEORY, LOCAL COOPERATIVISM}

Such actions can be based on the Theory of Social Cooperatives (SCT) which holds that the formation of cooperative networks would allow the construction of a collective identity endowed with skills, knowledge and values that allow the local development of the sectors vulnerable, marginalized and excluded (Figueroa et al., 2017).

The SCT proposes that the problems exposed are the result of a process of reproduction of social domination.

If the materialist conception of history warns that it is the relations of production that determine the asymmetry of power between social classes, the historical perspective of social domination suggests that the relations of production are the result of the resources available to an individual. Since it is not the classes, but the groups that establish power relations. That is, the environmental problems are caused by consumerist style, but it No prevents austerity is used to exclude, marginalize or dominate a group (Ceron, 2012).

This is how the relations of production are circumscribed to the symbols that anticipate the emergence of a reproduction of power. In the case of social injustice or child labor, both are examples of social domination that a sector assumes as an identity and around it develops ways of life and around them subjugate their opportunities to the capabilities of others, or, reify their values following consumer lifestyles (Fortich and Moreno, 2012). 
In any case, the reproduction of knowledge as well as skills or values is the product of canceled opportunities for a sector. Consequently, the capacities that are generated from the freedoms of choice are indicative of social reproduction, underlying discursive scenarios, capital networks or cooperative habitus (Capdevielle, 2011).

In effect, cooperativism consists of two paths, generates domination and its reproduction. It is used by financial networks to produce wealth or reproduce monopolies, but it is also used by networks of workers to generate wealth, according to surplus value or poverty according to conformism (Joignant, 2012).

Once the networks of capital have been formed, there are spaces of conflict in which symbols are instruments of power and social domination. In the case of child labor, non-remuneration is more than a characteristic, it means a struggle of generations in which adults instruct children to submit to their designs (Martínez, 2013).

The symbolic world of children is collapsed by the rules of adults, not only infants are dominated by their economic condition, but by their creativity that contrasts with the asymmetrical lives of adults.

In this sense, the SCT is insufficient since it does not explain the differences between generations in order to anticipate scenarios of conflict and domination in which its reproduction is interrupted or exacerbate.

Cooperativist Theory of Habitus (HCT) shows how ethical, logical, gestural and aesthetic learning are instruments of resistance of infants to the onslaught of adult domination and the reproduction of economic asymmetries (Amemiya et al, 2018).

If the sociohistorical conflict, according to the Marxist theory is made from the State, social domination, from the HCT approach gestates in the lifestyles and internal processes leaving aside the material conditions of existence or the environment of power and the relationships of social influence (Castro, 2011). 
The HCT maintains that the environmental, social, labor or educational problems are the product of the perspective of culture that the individual is constructed. A vision of network culture assumes that trust and empathy are the basis for consensual participation or the emergence of collaborative nodes, knowledge groups or social management (Soto et al., 2018).

\section{STUDIES OF LOCAL COOPERATIVIST WORK}

The state of knowledge has developed eight dimensions from which the Social Work Cooperative has developed, although there may be more, the promotion of habitus, field management, dissemination capital, networking, establishing rules Cooperation, mediation of trust, intentionality of satisfaction and professional training are indicative of a new proposal (Gutiérrez et al., 2019).

However, the diversity of problems and their effects on the lifestyles of vulnerable, marginalized or excluded sectors requires new indicators from which the TSC anticipates scenarios of dialogue, discussion, consensus and socio-political identity (García, 2014).

The TSC proposal is based on the analysis of the relationship between society and the State, which in the contexts of the SCT and the HCT considered science and technology as the factors for the dissemination of skills and knowledge that would allow the control of nature for economic development (García et al., 2017).

In this scenario, natural resources, social injustices, working conditions and educational problems were seen as collateral effects of the anthropocentric and ethnocentric realm of nature, the proletariat or educational formation.

However, the subjugated groups and individuals that responded to this project of modernity, were seen as dissidents or deviant due to the fact of forming criminal cooperative or solidarity networks (García, 2017).

The fact is that globalization neoliberal modernism underestimated the alternatives to development that were built in the periphery and ignored the opportunity to observe in these emerging networks its internal dynamics since these minorities are product of market demands and available natural resources (Veliz et al., 2018). 


\section{SPECIFICATION OF A LOCAL COOPERATIVE WORK MODEL}

Given that the neoliberal globalizing modernity has the purpose of ignoring the vulnerable, marginalized and excluded sectors, it is necessary to propose eight new functions of the TSC: empathy, ecocentrism, altruism, biosphericism, austerity, reuse, satisfaction and happiness.

Each of these dimensions corresponds to the issues raised, however, together they provide an integral perspective that the TSC can acquire to disseminate skills, values, and knowledge according to opportunities, but above all to the responsibilities that individuals must assimilate (Zambrano, 2010).

Think of the case of child labor, empathy is the foundation of collaborative rather than conflictive relationships, as long as it is based on beliefs that natural resources are scarce and that they directly affect vulnerable groups. Therefore, the altruism that was the antecedent of Social Work, unlike the past, is no longer based on benevolence, but consists of a scholarship system, although similar to rewards and stimuli. Includes the formation of values of respect for nature.

Lifestyles and technologies aimed at the optimization of resources are two essential elements in the construction of a biospheric and ecocentric identity, but they would not be sufficient without satisfaction and happiness, no longer as the heritage of the wealthy and affluent sectors, but as symptom of subjective well-being and objective quality of life (García, 2017).

In sum, the eight indicators allow to reveal a TSC that helps to form identities that due to their diversity can innovate in proposals built from agreements.

\section{FINAL CONSIDERATIONS}

The present document has proposed the axes of discussion and guidelines that allow the construction of Social Work oriented to the mediation of conflicts and the management of cooperatives for the endogenous development of the communities.

In reference to other works related to Social Work and the Sustainable Development, Carreón (2014), García (2014) and Hernández (2014) state that natural resources assumed as public services are governed by supply policies in which consensus it lies in internal rather than public negotiations. 
In contrast, in this paper it is noted that the asymmetric relations between authorities and users are the result of habitus, fields and capitals of reproduction of social domination, but susceptible to both subjugation and the recognition and vindication of vulnerable, marginalized or Excluded

The contribution of the present work lies in the conceptualization of eight dimensions related to Social Work in communities and cooperatives for Local Development. From the description of global issues that affect the municipal sphere, the scope and limits of the Theory of Social Cooperativism were discussed in order to establish the studies that contribute to the state of knowledge. Once the literature was considered, eight dimensions were formulated for the practice of Cooperativist Social Work.

However, the proposal of this work contravenes the reviews that have been published regarding Social Work and Local Development, although unlike these, it is stated that endogenous development is a scenario of favorable dispositions to the environment, social justice and child development.

Finally, the proposal does not end with the model used, but it is noted that the limits of Cooperativist Social Work are related to forms of social domination rather than freedoms, opportunities, abilities or responsibilities. That is, social conformity and group innovation are only two indicators of cooperation that serve to assess the asymmetries between the rulers and the governed.

\section{REFERENCES}

Amemiya, M., Valdés, O., Morales, F. and García, C. (2018). Specification of a model for the study of sustainable local development. Eureka, 15 (1), 36-57

Barranco, C., Delgado, M., Melin, C. and Quintana, R. (2010). Social work in housing: research on perceived quality of life. Portularia, 10, 101-111

Capdevielle, J. (2011). The concept of habitus. Anduli. Andalusian Journal of Social Sciences, 10, 31-45

Carreón, J. (2014). Towards the consensual management of water resources. Interdisciplinary, 31 (1), 1-12 
Carreón, J.,Hernández, J. and García,C. (2016). Public agenda and sociopolitical participation. Fermentum, $26,41-56$

Castro, M. (2011). Linguistic habit and right to information in the medical field. Revista Mexicana de Sociología, 73, 231-259

Cerón, A. (2012). Habitus and capitals: Provisions or social devices? Teóric notes as metodológic as for social research. Latin American Journal of Methodology of Social Research, 4, 68-82

Eito, A. (2012). The user's participation in social work. A look from the present towards the conception of humanism. Actions and Social Investigations, 32, 245-255

Figueroa, O., Fierro, E., Martinez, J. Chávez, JC and García, C. (2017). Governance of the economy 4.0: Contrasting a model of the perceptual determinants of self-employment.Psychology, 8 (2), 47-59

Fortich, M. and Moreno, Á. (2012). Elements of field theory. Verba luris, 27, 47-62

France, A. (2011). Reflections on the Second World Conference on: Social Work and Social Development, actions and impacts. Directions, 7, 22-31

Fuentes, V., Muyor, J. and Galinda, Z. (2010). Social work and new forms of care reorganization. An approximation to the purpose of the law of dependence. Alternatives, 17, 83-102

García, C. (2014). The professional training of human capital in the civilization of climate change. International Journal of Research in Social Sciences, 10, 107-125

García, C. (2017). Specification of a model for the study of labor interculturalism. Perspectives, 30, 83-109

García, C., Bustos, J.M., Carreón, J. and Hernández, J. (2017). Theoretical and conceptual frameworks around local development. Margin, 85, 1-11 
García, C., Carreón, J. and Hernández, J. (2017). Co-management as a security device for local sustainable development. Eureka, 14 (2), 268-289

García, C., Juárez, M. and Bustos, JM (2018). Specification of a model for the study of local governance. Synchrony, 22 (73), 459-472

Gutiérrez, JM, García, C., Valdés, O., Anguiano, F., Sandoval, FR and Campos, G. (2019). Citizenship expected in its perceived contemporaneity. Interstices, 13 (1), 87-97

Hernández J. (2014). Sociopolitical complexity of public transport. Implications for Sustainable Local Development. Reason and Word, 86, 1-27

Joignant, A. (2012). Habitus, field and capital. Elements for a general theory of political capital. Revista Mexicana de Sociología, 74, 587-618

Martínez, E. (2013). The problematic genesis of the concept of habitus. Revista Mexicana de Sociología, 75, 125-131

Morera, N. (2010). The link between the social sciences and social work: some elements for discussion. Reflections, 89, 235-241

National Institute of Statistics Geography and Informatics (2010). Women and men in Mexico. Mexico: INEGI

National Institute of Statistics, Geography and Informatics (2010). Child labor in Mexico. Mexico: INEGI

Quiroga, M., Vargas, F. and Cruz, A. (2010). Social work and social responsibility: notes for an ideological discussion. Tabula Rasa, 12, 175-193

Soto, A., Dorner, A., Garcia, C. and Hernández, TJ (2018). The collective welfare as a topic of family re-socialization in the society of informational capitalism. Utopia and Latin American Praxis, 23 (83), 52-56 
Váldés, O., Amemiya, M. and García, C. (2019). Specification of a model for the study of the establishment of multiple water sustainability agendas. Synchronism, 25 (75), 281-298

Veliz, A., Carreon, J., Dorner, A., Estay, JG and Garcia, C. (2018). Democracy, governance and ethical behaviors: transversal axes of training. Option, 34 (86), 152-175

Villegas, E., Rosas, F.J. and García, C. (2018). Social Works towards a quality of life and wellbeing subjective. International Journal of Research in Humanities and Social Studies, 5 (6), 1-14

Zambrano, C. (2010). Nature, culture and development. Contextual social work agenda. Portularia, $10,111-124$ 